\title{
Uncovering LED light effects on plant growth: new angles and perspectives - LED light for improving plant growth, nutrition and energy-use efficiency
}

\author{
Z. Bian ${ }^{1}$, N. Jiang², S. Grundy ${ }^{2}$ and C. Lu 2 a \\ ${ }^{1}$ School of Animal, Rural and Environmental Sciences, Nottingham Trent University, Nottingham, United Kingdom; \\ ${ }^{2}$ School of Biosciences, University of Nottingham, Loughborough, United Kingdom.
}

\begin{abstract}
Light supplementation can increase crop yield in greenhouses by promoting photosynthesis and plant growth. However, the high energy costs associated with light supplementation are a predominant factor that limits development and profit improvement of controlled environment agriculture. Light-emitting diodes (LEDs) are a promising technology that has tremendous potential to improve irradiance efficiency and to replace traditionally used horticultural lighting. Compared with traditional light sources (e.g., high-pressure sodium lamps and metal halide lamps) used in crop production, LEDs have distinct advantages, such as their small size, long lifetime and high photoelectric conversion efficiency. Most importantly, as a monochromatic light source, the spectrum of LEDs can be adjusted based on plant growth requirements. This project aimed to investigate energy-use efficiency, vegetable nutrition and photosynthesis improvement of light supplementation in a protected horticulture system. In the initial phase, the effects of LED light on plant growth and light-use efficiency for pak choi and photosynthetic performance were investigated. The results showed that the highest fresh and dry weight and leaf area were observed under red and blue LED light, with the blue light percentage at $23 \%$. Compared with fluorescent lamps (FL) with photosynthetic photon flux density (PPFD) at $220 \mu \mathrm{mol} \mathrm{m} \mathrm{m}^{-2} \mathrm{~s}^{-1}$, the light-use efficiency increased by 55, 114 and $115 \%$ for mixed red and blue LEDs with PPFD at 100, 150 and $220 \mu \mathrm{mol} \mathrm{m}^{-2} \mathrm{~s}^{-1}$, respectively. Monochromatic red- and blue-light LEDs resulted in significant decreases in $P_{n}$ of tomato plants, but the stomatal conductance $\left(G_{s}\right)$ for monochromatic blue LEDs was higher than that for FL. The effect of light spectrum composition on lettuce nutrition quality was also studied. Continuous light with combined red, green and blue LEDs exhibited a remarkable decrease in nitrate. Moreover, continuous LED light for $24 \mathrm{~h}$ significantly increased phenolic compound content and free-radical scavenging capacity in lettuce leaf.
\end{abstract}

Keywords: LEDs, light quality, photosynthesis, energy-use efficiency, nitrate content, phenolic compounds

\section{INTRODUCTION}

Greenhouses have been introduced into commercial crop production for several decades. Currently, small industries and individuals have been involved in urban farming with success in producing fresh food, in a sustainable way, able to deliver to the final consumer in an instant, without transportation costs or storage needs. Also, people that encounter these kinds of businesses and taste the products tend to prefer them, because they are healthier, fresher and last much longer than the imported equivalents. Light is one of the most important factors in plant growth development. Light is not only the energy for driving photosynthesis, but an essential signal to mediate downstream gene expression of substance metabolism for the plant to acclimate to environmental fluctuation (Chen et al.,

${ }^{\mathrm{a} E-m a i l: ~ c h u n g u i . l u @ n t u . a c . u k ~}$ 
2004). In the commercial greenhouse, light supplementation using artificial light can significantly increase crop yield and nutrition quality, especially in low-light-intensity seasons like winter and late autumn (Lu et al., 2012; Yorio et al., 2001). With the development of urban agriculture, artificial light has become the most important way to control the light conditions. For a long time, people were using fluorescent lamps, filament lamps and high-pressure sodium lamps (HPL), and much research was carried out to test their effects (Tibbitts et al., 1983). However, these kinds of light tend to consume large amounts of electrical energy and release a lot of heat (which will also increase the cooling system cost), and their spectra are not very suitable for plants, which leads to excessive waste of energy (Randall and Lopez, 2014). The most important element in controlling artificial farming costs is supplying light for photosynthesis and growth by light sources with high photoelectric efficiency. Light-emitting diodes (LEDs) have been proposed as alternative light sources in controlled agricultural environments since, compared with traditional horticulture light sources (e.g., HPL), LEDs have drastic advantages, such as superior lifetime, reduced size, cooler emitting temperature, and reduced energy consumption (Massa et al., 2008). An exciting potential of using LED lighting is the development of species-specific light recipes comprising the optimum proportion of specific narrow-band wavelength light that can optimize plant growth, development and other desirable traits (e.g., increase phytochemical content) (Bian et al., 2015, 2016), whilst significantly reducing the energy input compared with traditionally used horticulture light sources. Recently, the effect of LEDs on plant growth and development has aroused increasing interest. However, the results of related studies are sometimes different, and even contradictory (Avercheva et al., 2009; Bian et al., 2016; Hogewoning et al., 2010; Urbonavičiūtė et al., 2007). A hypothesis has been raised that the different application strategies might arouse different responses of plants to LED light treatments. We conducted experiments using different light spectral compositions and application strategies of LEDs to further reveal the disadvantages of LEDs in energy saving and plant nutrition quality improvement.

\section{MATERIALS AND METHODS}

\section{Plant material and growth conditions}

\section{Experiment I.}

Pak choi (Brassica rapa 'Bonsai', Chinensis group) seeds were sown in commercial substrate and germinated in an environment-controlled growth chambers. After germination, seedlings were randomly treated with red (650-670 nm; R) and blue (455-475 $\mathrm{nm}$; B) LEDs (Green power research module, Philips) with four different R/B ratios for 14 days. The spectral compositions of light treatments are summarized in Table 1. The photosynthetic photon flux density (PPFD) of all light treatments for pak choi was maintained at $130 \mu \mathrm{mol} \mathrm{m}^{-2} \mathrm{~s}^{-1}$ through adjusting the distance between the light sources and plants. In the next step, pak choi seedlings were grown under mixed red and blue LED light, but with high $\left(220 \mu \mathrm{mol} \mathrm{m}^{-2} \mathrm{~s}^{-1}\right)$, medium $\left(150 \mu \mathrm{mol} \mathrm{m}^{-2} \mathrm{~s}^{-1}\right)$ and low $\left(100 \mu \mathrm{mol} \mathrm{m}^{-2} \mathrm{~s}^{-1}\right)$ light intensities to investigate light-use efficiency. Pak choi grow under fluorescent lamps (FL; Unigro, $12 / 6 \mathrm{~N}$ ) with a PPFD at $220 \mu \mathrm{mol} \mathrm{m}^{-2} \mathrm{~s}^{-1}$ were used as a control. Each treatment light had triple replications (four or five plants per replication). In the growth chamber, photoperiod, day/night temperature, relative humidity and $\mathrm{CO}_{2}$ level were set at $16 \mathrm{~h}$, $25 \pm 1 / 20 \pm 1^{\circ} \mathrm{C}, 65 \pm 5 \%$ and $400 \pm 20 \mathrm{ppm}$, respectively.

\section{Experiment II.}

Tomato (Solanum lycopersicum) seeds were sown in commercial substrate and grown under FL (Unigro, 12/6N) with a PPFD at $150 \mu \mathrm{mol} \mathrm{m}^{-2} \mathrm{~s}^{-1}$. Every other day, tap water was added from the bottom of the pots to keep the substrate wet. When plants had their second true leaves, they were randomly treated with monochromatic red (650-670 nm, R) LEDs, monochromatic blue (455-475nm; B) LEDs, or mixed red and blue LEDs (R/B=1). Plants 
grown under FL were used as a control. Every other day, light intensity was monitored with a spectrometer (Skye Instruments Spectra Sense, RS 232). Light intensity for all the light treatments was kept at $200 \mu \mathrm{mol} \mathrm{m}{ }^{-2} \mathrm{~s}^{-1}$ by adjusting the distance between the light sources and the top of the plants. Other environment factors were the same as in experiment I.

Table 1. Light spectral composition details.

\begin{tabular}{lcc}
\hline Treatment & Red light (\%) & Blue light (\%) \\
\hline $0 \%$ & 100 & 0 \\
$23 \%$ & 77 & 23 \\
$27 \%$ & 73 & 27 \\
$30 \%$ & 70 & 30 \\
$62 \%$ & 62 & 38 \\
$100 \%$ & 0 & 100 \\
\hline
\end{tabular}

\section{Experiment III.}

Lettuce (Lactuca sativa L.) was seeded in plastic seedling trays filled with peat:vermiculite $(3: 1, \mathrm{v} / \mathrm{v})$ and grown in a controlled growth chamber. Fluorescent lamps (T5, PHILIPS) were used as light sources for seedling cultivation and light intensity was maintained at $100 \mu \mathrm{mol} \mathrm{m}^{-2} \mathrm{~s}^{-1}$. The other environmental factors were set as in experiment $\mathrm{I}$. When seedlings had their second true leaves, they were transplanted into a hydroponic growth system and grown under white (400-700 nm; W), LED light and combined red (peak at $660 \mathrm{~nm} ; \mathrm{R}$ ) and blue (455-475 nm; B) LED light with/without green (515-545 nm; G). The light intensity and photoperiod were $200 \mu \mathrm{mol} \mathrm{m} \mathrm{m}^{-2} \mathrm{~s}^{-1}$ and $12 \mathrm{~h}$, respectively and other environmental factors were as described in experiment I. Before harvesting, lettuce plants were conducted continuous light treatment for $24 \mathrm{~h}$. The light treatment details are summarized in Table 2. These LED light sources (VQ-G200; Vanq Technology, Shenzhen, China) were maintained at $20 \mathrm{~cm}$ above the canopies of the plants. The PPFD of the LED light sources was monitored daily by a quantum sensor (LI-190SA; LI-COR, Lincoln, NE, USA).

Table 2. Light spectral details for continuous lighting.

\begin{tabular}{lcccc}
\hline \multirow{2}{*}{ Treatment } & \multicolumn{2}{c}{ Before treatment } & \multicolumn{2}{c}{ Continuous light treatment } \\
\cline { 2 - 5 } & Light source & $\begin{array}{c}\text { Spectral ratio } \\
\text { (red:blue:green) }\end{array}$ & Light source & $\begin{array}{c}\text { Spectral } \\
\text { ratio }\end{array}$ \\
\cline { 2 - 5 } W & White LEDs & $0.4: 1: 1$ & White LEDs & $0.4: 1: 1$ \\
RB & Red and blue LEDs & $4: 1$ & Red and blue LEDs & $4: 1$ \\
RBG & Red and blue LEDs & $4: 1$ & Red and blue LEDs plus green & $4: 1: 1$ \\
& rb & & LEDs & \\
& Mixed red, blue and green & $1: 1: 1$ & Red and blue LEDs & $1: 1$ \\
\hline
\end{tabular}

\section{Plant growth determination}

Pak choi seedlings were sampled after treatment with different light spectra for 7 days. Plants were cut from the hypocotyl. The shoots were weighed and then dried in an oven at $72^{\circ} \mathrm{C}$ to calculate shoot dry weight. Leaf areas were monitored using Li-3001C (LI-COR, Lincoln, NE, USA). To investigate energy-use efficiency, all plants were harvested to determine plant fresh biomass after 3 weeks of growth under different light intensities. The light-use efficiency was calculated as average fresh weight of plant divided by light source power used $\left(\mathrm{kW} \mathrm{h}^{-1}\right)$. Each measurement was repeated three times with three or four plants per replication.

\section{Gas exchange and chlorophyll $a$ fluorescent determination}

Gas exchange and chlorophyll a fluorescence were monitored according to the method 
of Yan et al. (2012). The minimum $\left(F_{o}\right)$ and maximum $\left(F_{m}\right)$ Chl fluorescence levels were determined after the leaves had been dark adapted for 30 min. Photosynthesis, stomatal conductance and chlorophyll fluorescence measurements were taken after the leaf reached steady-state photosynthesis at $150 \mu \mathrm{mol} \mathrm{m}^{2} \mathrm{~s}^{-1}$ light of the same red/blue proportion as its growth conditions during treatment. The maximal quantum yield $\left(\mathrm{F}_{\mathrm{v}} / \mathrm{F}_{\mathrm{m}}\right)$ and the effective quantum yield $\left(\Phi_{\text {PSII }}\right)$ were calculated as $F_{v} / F_{m}=\left(F_{m}-F_{o}\right) / F_{m}$ and $\Phi$ PSII $=\left(F_{m}{ }^{\prime}-F_{s}\right) / F_{m}{ }^{\prime}$, respectively.

\section{Determination of total phenolic compounds and 2,2-diphenyl-1-picrylhydrazyl (DPPH) free-radical scavenging capacity}

Total phenolic compound concentrations were determined spectrophotometrically (Ragaee et al., 2006) with slightly modifications. The free-radical-scavenging capacity of the lettuce leaf under continuous lighting was evaluated by the DPPH free-radical scavenging capacity, as described by Ragaee et al. (2006).

\section{Nitrate content measurements}

The method of Cataldo et al. (1975) was used to evaluate nitrate content in lettuce leaves treated with different continuous lighting. Briefly, $2.0 \mathrm{~g}$ leaf samples were ground with liquid nitrogen using a mortar and pestle. The sample powder was transferred into a tube with $10 \mathrm{~mL}$, and boiled for $30 \mathrm{~min}$ at $100^{\circ} \mathrm{C}$ in a water bath. The extracted samples were cooled with tap water, filtered, and diluted to $25 \mathrm{~mL}$ with distilled water. The extract $(0.1 \mathrm{~mL})$ was further diluted with $0.4 \mathrm{~mL} 5 \%(\mathrm{w} / \mathrm{v})$ salicylic acid/concentrated sulfuric acid. After reaction for $20 \mathrm{~min}, 9.5 \mathrm{~mL} 8 \%(\mathrm{w} / \mathrm{v}) \mathrm{NaOH}$ solution was added. The absorbance monitored at $410 \mathrm{~nm}$ was used to calculate nitrate content with respect to its standard curve.

\section{Statistical analysis}

At the data were subjected to one-way ANOVA using SAS 9.0 software (SAS Institute, Cary, NC, USA). Significant differences between treatments were evaluated by Duncan's multiple range test at $p<0.05$.

\section{RESULTS}

\section{Effects of light spectral composition on pak choi growth}

Shoot fresh and dry weights and leaf areas were significantly affected by the blue light percentage in the light source (Figure 1A-C). The fresh and dry weight of shoots and leaf area were the highest under the 23\% blue light treatment, followed by 27 and $100 \%$ blue light treatments. The lowest values of these parameters were obtained under the monochromatic red light ( $0 \%$ blue) light treatment. Furthermore, there was a significant linear correlation between fresh weight and leaf area of pak choi (Figure 1D).

\section{Light energy-use efficiency under different light intensities}

There were significant differences in plant fresh weight and light-use efficiency under different light intensities (Figure 2). Under the same light intensity $\left(220 \mu \mathrm{mol} \mathrm{m}^{-2} \mathrm{~s}^{-1}\right)$, the fresh weight of plants under red and blue LEDs was comparable to that of FL (control), but a decrease in light intensity of combined red and blue LEDs resulted in a significant decrease in shoot fresh weight (Figure 2A). There was a significant difference in light-use efficiency between high light intensity and medium light treatment. Compared with FL, light-use efficiency increased by 55, 114 and $115 \%$ for mixed red and blue LEDs with PPFD at 100, 150 and $220 \mu \mathrm{mol} \mathrm{m}^{-2} \mathrm{~s}^{-1}$, respectively.

\section{Photosynthetic performance of tomato under different LED lights}

Tomato plants grown under the white LED light displayed significantly higher rates of photosynthesis than those grown under other LED light (Figure 3A). Plants grown under monochromatic red and mixed red and blue light exhibited similar photosynthetic rates, but plants grown under monochromatic blue light displayed significantly impaired rates of 
photosynthesis compared with other spectral compositions of light. Stomatal conductance was highest under monochromatic blue light, followed by white, mixed red and blue, and finally monochromatic red light (Figure 3B). Among different LED light treatments, there was no significant difference in $\mathrm{F}_{\mathrm{v}} / \mathrm{F}_{\mathrm{m}}$. The highest and lowest $\Phi_{\text {PSII }}$ were observed under white and mixed red and blue LED light, respectively. However, there was no significant difference between monochromatic red and blue light treatment in tomato leaf.
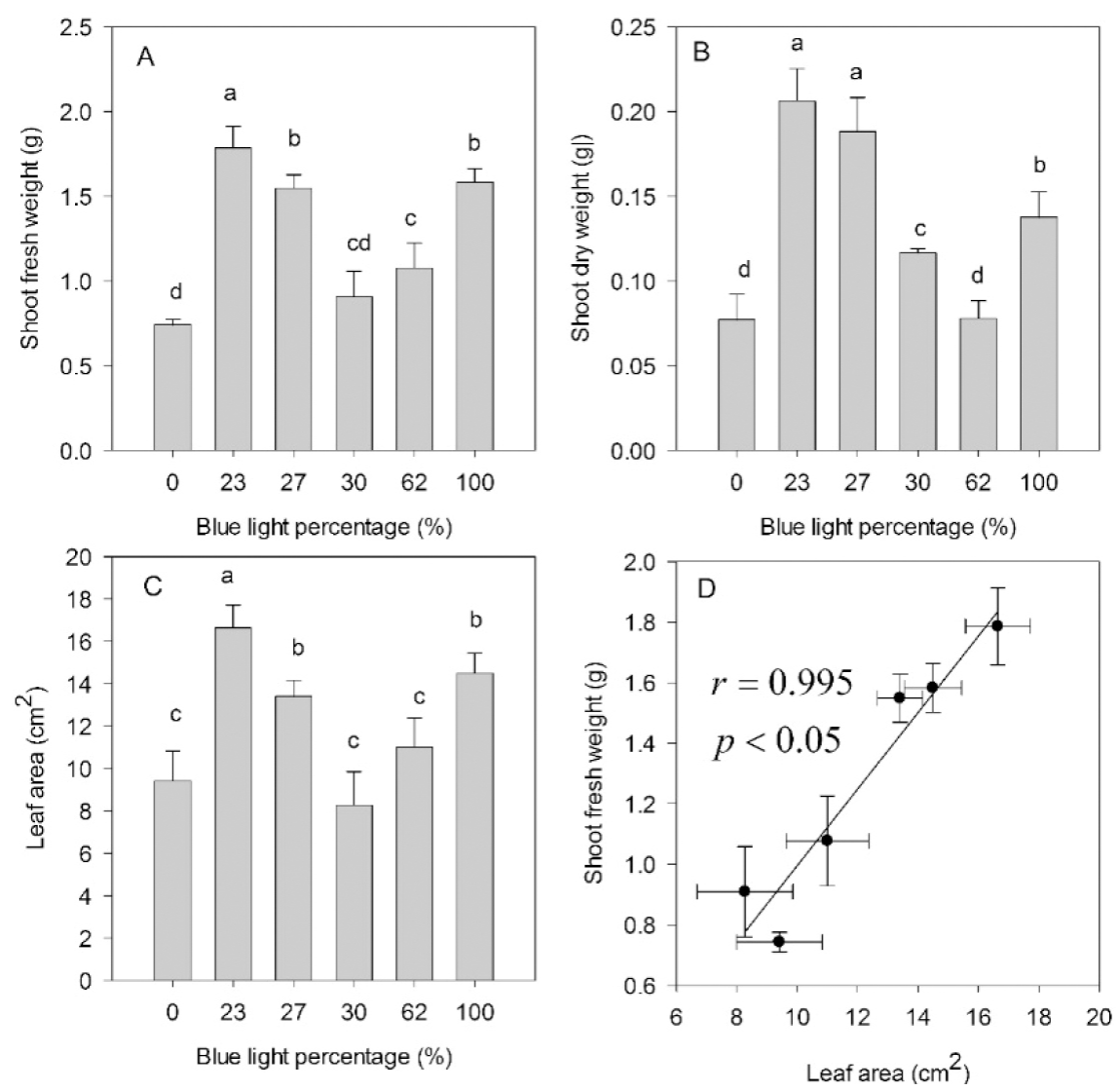

Figure 1. Effects of light spectra on pak choi growth (A-C) and the relation between leaf area and fresh weight (D).
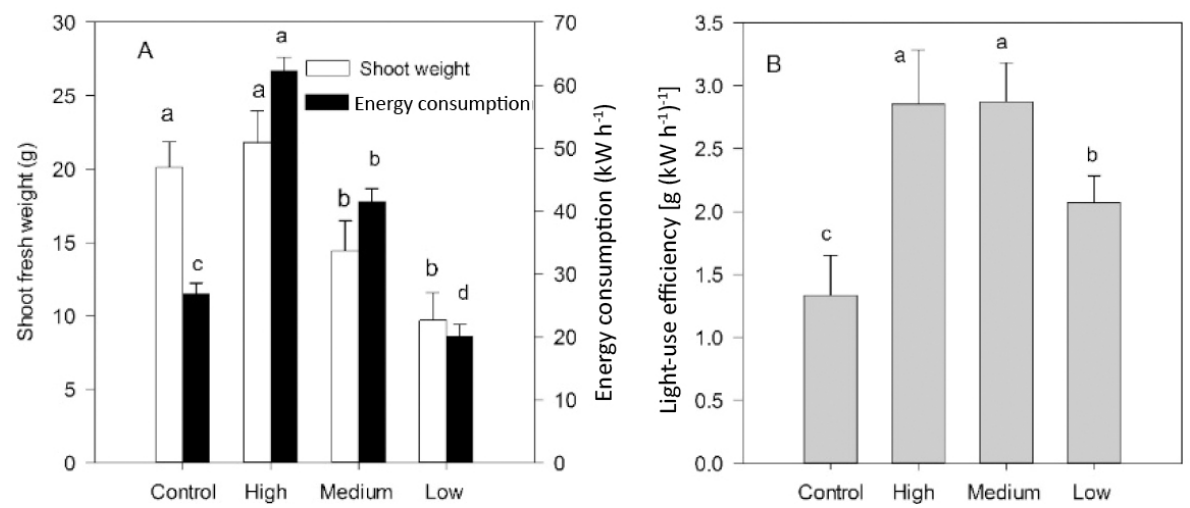

Figure 2. Shoot fresh weight of pak choi and energy-use efficiency under mixed red and blue LED light with high $\left(220 \mu \mathrm{mol} \mathrm{m}^{-2} \mathrm{~s}^{-1}\right)$, medium $\left(150 \mu \mathrm{mol} \mathrm{m}^{-2} \mathrm{~s}^{-1}\right)$ and low $\left(100 \mu \mathrm{mol} \mathrm{m}^{-2} \mathrm{~s}^{-1}\right)$ light intensity. 

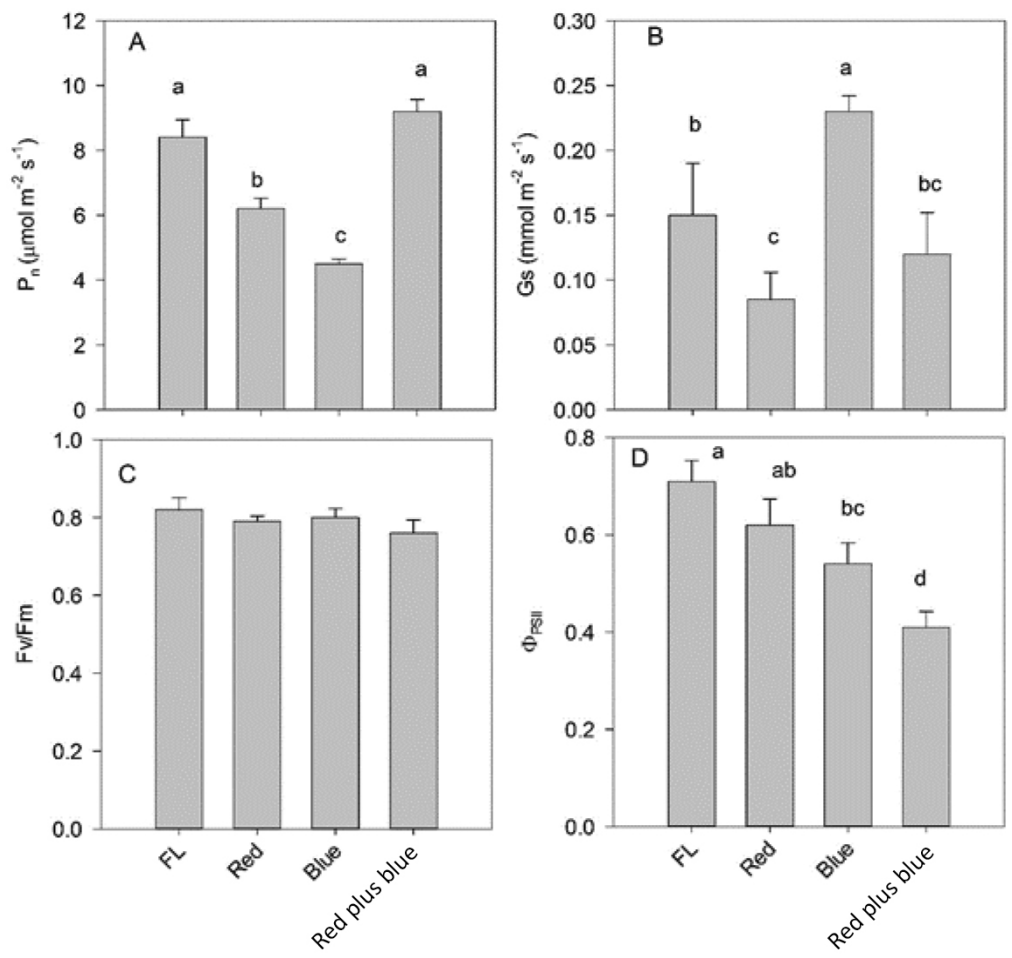

Figure 3. Effects of light spectral composition on photosynthetic performance of tomato seedlings.

\section{Effects of light spectra on nitrate content, total phenolic compounds and scavenging capacity in lettuce under continuous lighting}

Nitrate content, total phenolic compounds and free radical scavenge capacity were significantly affected by light spectral composition under continuous light (Table 3). Continuous light (except white LED treatment) for $24 \mathrm{~h}$ significantly decreased nitrate accumulation in lettuce leaves. The nitrate content was lowest under RBG treatment, followed by RB, rb and finally by W treatment. Total phenolic compounds and DPPH radical scavenging activity were both markedly increased after $24 \mathrm{~h}$ continuous light treatment. However, these parameters did not show significant differences among $\mathrm{W}$, RB and RBG treatments.

Table 3. Nitrate content, total phenolic compounds and scavenging capacity in lettuce after $24 \mathrm{~h}$ continuous lighting.

\begin{tabular}{|c|c|c|c|}
\hline Treatment & $\begin{array}{l}\text { Nitrate content } \\
\left(\mathrm{mg} \mathrm{kg}^{-1}\right)\end{array}$ & $\begin{array}{l}\text { Total phenolic compounds } \\
\left.\text { ( } \mathrm{mg} \mathrm{g}^{-1}\right)\end{array}$ & $\begin{array}{l}\text { DPPH radical scavenging activity } \\
\qquad\left(\mu \mathrm{mol} \mathrm{g} \mathrm{g}^{-1}\right)\end{array}$ \\
\hline Control & $509.4 \pm 22.1 \mathrm{a}$ & $1.34 \pm 0.06 c$ & $3.25 \pm 0.14 c$ \\
\hline W & $487.3 \pm 33.2 a$ & $1.69 \pm 0.03 a$ & $3.90 \pm 0.22 a$ \\
\hline RB & $324.7 \pm 28.7 \mathrm{c}$ & $1.70 \pm 0.07 a$ & $4.26 \pm 0.31 a$ \\
\hline RBG & $243.5 \pm 21.6 d$ & $1.74 \pm 0.11 \mathrm{a}$ & $4.18 \pm 0.12 a$ \\
\hline $\mathrm{rb}$ & $384.4 \pm 20.9 b$ & $1.53 \pm 0.06 \mathrm{~b}$ & $3.51 \pm 0.09 b$ \\
\hline
\end{tabular}

\section{DISCUSSION}

Light is not only the driving-force for photosynthesis but also as important signal to regulate gene expression in plants (Chen et al., 2004). Plant growth and development depend on light intensity, photoperiod, light spectral composition and light direction. In the present study, comparable $\mathrm{F}_{\mathrm{v}} / \mathrm{F}_{\mathrm{m}}$ of tomato plants were obtained under different light spectra (Figure 3), indicating that light spectral composition showed little effect on 
photosynthetic capacity (Osmond, 1994). In plants, there are four types of photoreceptors: phytochromes, cryptochromes, phototropins and UV-B receptors (UVR-8). These photoreceptors share distinct pathway to coordinately regulate transcriptional changes in response to light. Cross-talk among photoreceptors via transcription factors (e.g., HY5 and PIFs) leads to a more complex response of plants to light spectra (Su et al., 2017). Compared with monochromatic red and monochromatic blue LEDs, the significantly lower $\Phi_{\text {PSII }}$ but markedly higher $\mathrm{P}_{\mathrm{n}}$ under mixed red and blue LEDs might lie in coordinated regulation between phytochromes and cryptochromes under combined red and blue light conditions (Wade et al., 2001). Similar results were also reported by Karlsson (1986), who found that there was red and blue light enhancement under combined red and blue light treatment.

A suitable light spectral composition could compensate for the effect of light intensity on photosynthesis and alleviate limitation of low light intensity to photosynthesis (Fan et al., 2013). A similar result was also observed in our study, when different crops were grown under different light intensities and different compositions of light (Figure 2). Besides crop yield, the nutrition and flavour of vegetables are also important for human health, which arouses great concern around the word (Bian et al., 2015). Moderate abiotic and/or biotic stresses are conducive to phytochemical biosynthesis, especially secondary metabolites (Al Hassan et al., 2015). Plants develop complex antioxidant systems to acclimatize to fluctuations in the environment. The fast responses of antioxidant enzyme activities and secondary metabolite accumulation are an important pathway for plants to scavenge reactive oxygen species produced by biotic and/or abiotic stress (Blokhina et al., 2003). During crop or vegetable production, artificial moderate stress using LEDs could significant improve plant nutrition quality (Ma et al., 2014). Before harvest, continuous lighting with different light spectra significantly increased lettuce secondary metabolites and concomitantly reduced nitrate content, which poses a threat to human health (Table 3). This is consistent with the study of Steindal et al. (2016), which showed that pre-harvest light spectral composition significant affected broccoli flavour and nutritional compounds.

Spectral quality drastically effects growth and development. It will probably take several iterations of testing a wide-range of light recipes in order to identify the optimum light regime for growth, development and other desirable traits like flavour and nutrition of vegetables. LED light will make a great contribution to revealing the mechanism of light wavelength regulation of plant growth and substance metabolism. The many different phenotypes already observed between treatments offer many different avenues of exploration to identify the key downstream regulators that are being regulated by specific light signals. LEDs as monochromatic light sources can make flexible combinations based on plant growth requirements. This distinct advantage of LEDs not only provides great help in revealing the mechanism of the plant response to light spectra but also offers a new way to reduce the energy cost of commercial production of crops in the greenhouse.

\section{ACKNOWLEDGEMENTS}

The authors want to thank all their colleagues and students for their assistance in the research for this paper.

\section{Literature cited}

Al Hassan, M., Martínez Fuertes, M., Ramos Sánchez, F.J., Vicente, O., and Boscaiu, M. (2015). Effects of salt and water stress on plant growth and on accumulation of osmolytes and antioxidant compounds in cherry tomato. Not. Bot. Horti Agrobot. Cluj-Napoca 43 (1), 1-11 https://doi.org/10.15835/nbha.43.1.9793.

Avercheva, O., Berkovich, Y.A., Erokhin, A., Zhigalova, T., Pogosyan, S., and Smolyanina, S. (2009). Growth and photosynthesis of Chinese cabbage plants grown under light-emitting diode-based light source. Russ. J. Plant Physiol. 56 (1), 14-21 https://doi.org/10.1134/S1021443709010038.

Bian, Z.H., Yang, Q.C., and Liu, W.K. (2015). Effects of light quality on the accumulation of phytochemicals in vegetables produced in controlled environments: a review. J. Sci. Food Agric. 95 (5), 869-877 https://doi.org/10.1002/jsfa.6789. PubMed

Bian, Z.H., Cheng, R.F., Yang, Q.C., Wang, J., and Lu, C. (2016). Continuous light from red, blue, and green lightemitting diodes reduces nitrate content and enhances phytochemical concentrations and antioxidant capacity in 
lettuce. J. Am. Soc. Hortic. Sci. 141, 186-195.

Blokhina, O., Virolainen, E., and Fagerstedt, K.V. (2003). Antioxidants, oxidative damage and oxygen deprivation stress: a review. Ann. Bot. 91 (2), 179-194 https://doi.org/10.1093/aob/mcf118. PubMed

Cataldo, D., Maroon, M., Schrader, L., and Youngs, V. (1975). Rapid colorimetric determination of nitrate in plant tissue by nitration of salicylic acid 1. Commun. Soil Sci. Plant Anal. 6 (1), 71-80 https://doi.org/10.1080/ 00103627509366547.

Chen, M., Chory, J., and Fankhauser, C. (2004). Light signal transduction in higher plants. Annu. Rev. Genet. 38 (1), 87-117 https://doi.org/10.1146/annurev.genet.38.072902.092259. PubMed

Fan, X.X., Xu, Z.G., Liu, X.Y., Tang, C.M., Wang, L.W., and Han, X.L. (2013). Effects of light intensity on the growth and leaf development of young tomato plants grown under a combination of red and blue light. Sci. Hortic. (Amsterdam) 153, 50-55 https://doi.org/10.1016/j.scienta.2013.01.017.

Hogewoning, S.W., Trouwborst, G., Maljaars, H., Poorter, H., van Ieperen, W., and Harbinson, J. (2010). Blue light dose-responses of leaf photosynthesis, morphology, and chemical composition of Cucumis sativus grown under different combinations of red and blue light. J. Exp. Bot. 61 (11), 3107-3117 https://doi.org/10.1093/jxb/erq132. PubMed

Karlsson, P.E. (1986). Blue light regulation of stomata in wheat seedlings. I. Influence of red background illumination and initial conductance level. Physiol. Plant. 66 (2), 202-206 https://doi.org/10.1111/j.13993054.1986.tb02409.x.

Lu, N., Maruo, T., Johkan, M., Hohjo, M., Tsukagoshi, S., Ito, Y., Ichimura, T., and Shinohara, Y. (2012). Effects of supplemental lighting with light-emitting diodes (LEDs) on tomato yield and quality of single-truss tomato plants grown at high planting density. Environ. Control Biol. 50 (1), 63-74 https://doi.org/10.2525/ecb.50.63.

Ma, G., Zhang, L., Setiawan, C.K., Yamawaki, K., Asai, T., Nishikawa, F., Maezawa, S., Sato, H., Kanemitsu, N., and Kato, M. (2014). Effect of red and blue LED light irradiation on ascorbate content and expression of genes related to ascorbate metabolism in postharvest broccoli. Postharvest Biol. Technol. 94, 97-103 https://doi.org/10.1016/ j.postharvbio.2014.03.010.

Massa, G.D., Kim, H.H., Wheeler, R.M., and Mitchell, C.A. (2008). Plant productivity in response to LED lighting. HortScience 43, 1951-1956.

Osmond, C. (1994). What is photoinhibition? Some insights from comparisons of shade and sun plants. In Photoinhibition of Photosynthesis from Molecular Mechanisms to the Field (London, UK: Oxford Bios Scientific), p.1-24.

Ragaee, S., Abdel-Aal, E.S.M., and Noaman, M. (2006). Antioxidant activity and nutrient composition of selected cereals for food use. Food Chem. 98 (1), 32-38 https://doi.org/10.1016/j.foodchem.2005.04.039.

Randall, W.C., and Lopez, R.G. (2014). Comparison of supplemental lighting from high-pressure sodium lamps and light-emitting diodes during bedding plant seedling production. HortScience 49, 589-595.

Steindal, A.L.H., Johansen, T.J., Bengtsson, G.B., Hagen, S.F., and Mølmann, J.A. (2016). Impact of pre-harvest light spectral properties on health- and sensory-related compounds in broccoli florets. J. Sci. Food Agric. 96 (6), 19741981 https://doi.org/10.1002/jsfa.7307. PubMed

Su, J., Liu, B., Liao, J., Yang, Z., Lin, C., and Oka, Y. (2017). Coordination of cryptochrome and phytochrome signals in the regulation of plant light responses. Agronomy (Basel) 7 (1), 25 https://doi.org/10.3390/ agronomy7010025.

Tibbitts, T., Morgan, D., and Warrington, I. (1983). Growth of lettuce, spinach, mustard, and wheat plants under four combinations of high-pressure sodium, metal halide, and tungsten halogen lamps at equal PPFD. J. Am. Soc. Hortic. Sci. 108, 622-630.

Urbonavičiūtè, A., Pinho, P., Samuolienė, G., Duchovskis, P., Vitta, P., Stonkus, A., Tamulaitis, G., Žukauskas, A., and Halonen, L. (2007). Effect of short-wavelength light on lettuce growth and nutritional quality. Sodinink. Darzinink. $26,157-165$.

Wade, H.K., Bibikova, T.N., Valentine, W.J., and Jenkins, G.I. (2001). Interactions within a network of phytochrome, cryptochrome and UV-B phototransduction pathways regulate chalcone synthase gene expression in Arabidopsis leaf tissue. Plant J. 25 (6), 675-685 https://doi.org/10.1046/j.1365-313x.2001.01001.x. PubMed

Yan, H., Hu, X., and Li, F. (2012). Leaf photosynthesis, chlorophyll fluorescence, ion content and free amino acids in Caragana korshinskii Kom exposed to $\mathrm{NaCl}$ stress. Acta Physiol. Plant. 34 (6), 2285-2295 https://doi.org/10.1007/s11738-012-1029-4.

Yorio, N.C., Goins, G.D., Kagie, H.R., Wheeler, R.M., and Sager, J.C. (2001). Improving spinach, radish, and lettuce growth under red light-emitting diodes (LEDs) with blue light supplementation. HortScience 36 (2), 380-383. PubMed 